\title{
DISEÑO GRÁFICO Y LITERATURA
}

\author{
Eugenio Murillo Fuentes
}

\begin{abstract}
RESUMEN
El concepto "Diseño gráfico", utilizado por primera vez en 1922, surge en estrecha relación con la producción de libros y con la creación literaria. No obstante, sus orígenes se remontan mucho tiempo atrás, a los albores del alfabeto. Así, Diseño gráfico y Literatura, junto con los sustratos y los medios de impresión, conforman una hermandad inseparable y cuentan con una historia común.
\end{abstract}

\begin{abstract}
The concept of "Graphic Design", used for the first time in 1922, arises in close relation of the production of books and literary creation. Never the less, its origin date back many years, to the dawning of the alphabet. This way, "Graphic Design" and Literature, together with sustrates and printing means, form an inseparable brotherhood and shave a common history.
\end{abstract}

Es probable que el nombre de este artículo resulte, en primera instancia, extraño para algunos lectores y que surja la pregunta de porqué ubicar juntas, en el título, estas dos actividades. Una reacción así es fácil de entender si se parte de que priva un conocimiento superficial o bien, muy ambigüo, de lo que significa Diseño Gráfico. En nuestros días, el concepto "Diseño Gráfico" se suele asociar comúnmente y casi en forma exclusiva, con la publicidad, lo cual es una perspectiva reducida, pobre y demasiado simplista. El concepto — que surgió entretejido a la producción de libros - ha ido evolucionando y creciendo con los años, hasta convertirse en una constelación muy basta, no tan fácil de visualizar; con más razón para quienes están fuera de ese campo profesional. No obstante, el Diseño Gráfico y las prácticas de escritura —incluida, por supuesto, la Literatura — han estado siempre en estrecha relación, incluso desde mucho antes de que Gutenberg inventara la imprenta en la primera mitad del siglo XV. Basta con mirar hacia atrás y hacer un recorrido por la historia de occidente para comprender mejor esa alianza, que surge con el nacimiento mismo del alfabeto.

\section{Origen y desarrollo del alfabeto latino}

Son varias las teorías que han tratado de explicar el origen del alfabeto latino. La más reciente y de mayor credibilidad fue propuesta, después de la Primera Guerra Mundial, por el 
erudito finlandés M. Hammrström. Su teoría descarta que el alfabeto latino fuera un préstamo del alfabeto griego, y más bien demuestra que es un derivado del alfabeto etrusco temprano, el cual sirvió de enlace entre la escritura griega y la latina (En Földes 1987: 175). Es decir, tanto el alfabeto griego como el etrusco son parte de su fundamento.

El historiador norteamericano James H. Breasted dice que "la invención de la escritura y de un sistema cómodo de transmisión de apuntes al papel ha tenido una influencia mucho mayor en el desarrollo del género humano, que cualquier otro progreso intelectual en la historia de la Humanidad" (En Haarmann 1991: 14). La importancia que se le da a la escritura es tal que las ciencias históricas la proponen incluso como frontera entre la Prehistoria y la Historia, correspondiendo la Prehistoria al período en que aún no se conocía esa forma gráfica de reproducir la comunicación verbal. Según las teorías más recientes, los intentos más antiguos de comunicación gráfica datan de hace unos 7.000 años y los indicios más antiguos de escritura a base de letras datan, aproximadamente, de los 2.000 años a. C., en el pueblo fenicio. No obstante, no fue el pueblo fenicio la única cuna de la escritura y se tienen pruebas de que ésta se inventó en distintos lugares, en tiempos y en áreas culturales independientes unas de las otras. Al respecto, Haarmann considera como condiciones específicas del origen de la escritura, por una parte "la necesidad de conservar informaciones en forma duradera (para su reutilización) y, por otra, la motivación surgida de eso mismo, de utilizar la escritura en forma continuada"(1991: 362). El desarrollo de la escritura está muy ligado al cambio de la vida nómada a la sedentaria. Primero surgieron los pictogramas, luego se pasó a los signos, equivalentes a palabras. Con la escritura de letras fue dado el último paso hacia la escritura universal en todos los idiomas. "El alfabeto fonético es una tecnología única. Ha habido muchas clases de escrituras, pictográficas y silábicas, pero no hay más que un solo alfabeto fonético en el que las letras, que semánticamente carecen de sentido, se emplean para que correspondan a sonidos también carentes de significado semántico" (McLuhan 1972: 115).

Fue a partir del siglo II antes de Cristo que poco a poco las letras del alfabeto latino alcanzaron su forma clásica. "En su diseño contribuyeron tanto el sentido griego por la belleza, como el gusto romano por la claridad y la sencillez práctica" (Földes 1987: 180). Las bases del diseño tipográfico occidental quedaron establecidas por los diseñadores de aquella época. Hoy se sabe que las letras eran primero dibujadas con un pincel sobre la piedra, poniendo especial cuidado a los contornos y a los espacios negativos, así como a los espacios entre cada una de las letras. Luego se daba paso a la precisión del arte del albañil. Algunos alfabetos actuales, presentes muchos de ellos incluso en nuestras computadoras, son derivados directos de los diseños de las letras de la Antigüedad. Tal es el caso de la letra Times, diseñada en 1923 especialmente para el diario inglés The Times (Müller-Brockmann 1982: 27) y tan común en nuestro medio actual.

Nuestro alfabeto latino se lo debemos al encumbramiento de Roma y al imperio que de ella se deriva, el cual ya en el siglo I d. C. se extendía desde Inglaterra por el norte hasta Egipto por el sur, y desde España en el occidente hasta el golfo Pérsico en el oriente. El alfabeto se convierte así en un signo más del poder. Su representación visual evoluciona, se afina y se exalta. "Para celebrar a sus generales y sus victorias, Roma, que se enorgullecía de sus éxitos imperiales y de sus conquistas, creó diseños monumentales con forma de letras, como parte de las inscripciones en la arquitectura. Las inscripciones romanas eran diseñadas para lograr gran belleza y permanencia" (Meggs 1991: 60). Un importante y muy conocido ejemplo 
es la inscripción labrada en la Columna de Trajano en Roma, alrededor del año 114 d. C., y que aún hoy podemos admirar en toda su magnificencia (Fig. 1. Inscripción del zócalo). Allí se evidencia el aforismo romano que reza: "La palabra escrita permanece".

La primer escritura romana es conocida como capitalis quadrata por componerse sólo de mayúsculas. Sus diseños muestran una unión armoniosa entre formas angulares, arcos y líneas; en renglones uniformes sin elementos ascendentes o descendentes (Fig. 1). Las palabras se separaban unas de otras mediante puntos a media altura. Era la escritura del poder, utilizada ya desde el siglo III a. C. Con ella se grabaron gran cantidad de lápidas y paredes en

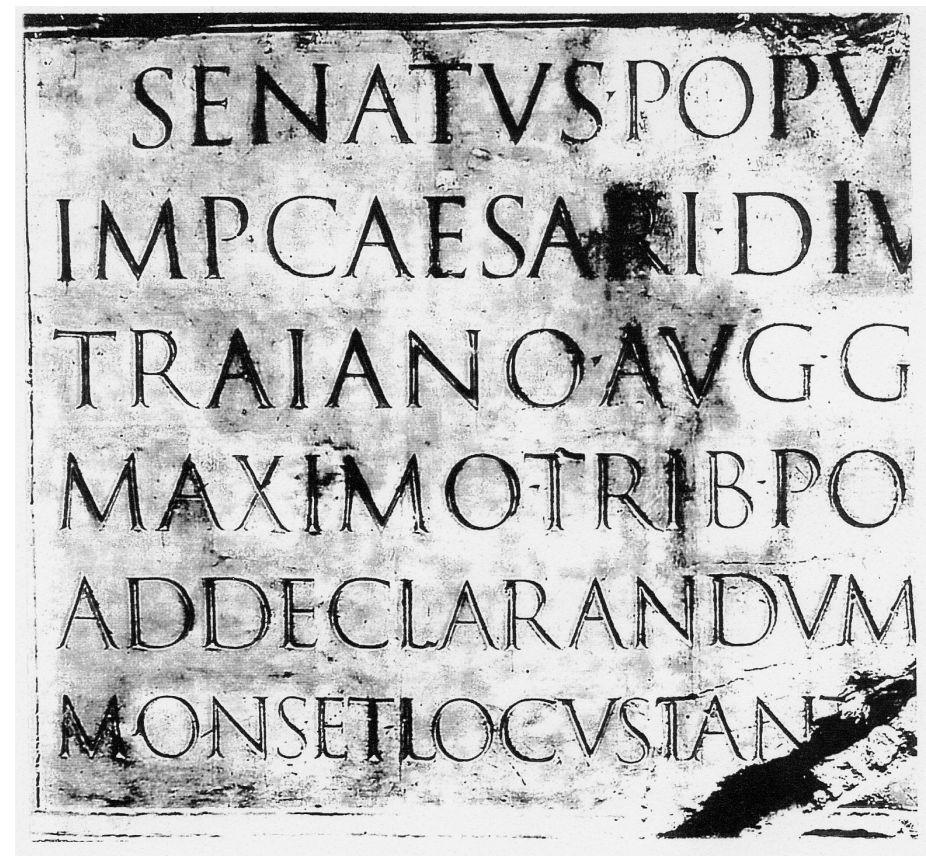

Figura 1

edificaciones imperiales, pues se concebía como la escritura para la posteridad. La capitalis quadrata, conocida también como "escritura capital", sufre algunas modificaciones en el siglo I d. C., con lo que surge así la escritura rústica (Fig. 2). La "rústica" evoluciona por esa misma época en la capital cursiva (Fig. 3), cuyo diseño algo frágil y menos imponente que el de su antecesora estaba condicionado por su uso cotidiano y por la necesidad de escribir con más rapidez. Tanto la escritura rústica como la capital cursiva se componían sólo de mayúsculas. No obstante, la letra capital cursiva incorpora trazos largos ascendentes y descendentes a partir del cuerpo básico de las mayúsculas. Esos trazos, condicionados por la necesidad de escribir cada vez con más libertad y rapidez, junto con la consecuente simplificación, darán paso a las letras de tres cuerpos. La escritura se va adaptando así a las necesidades de cada época, como derivado del ser humano, para su propia utilización. "La escritura es un medio de comunicación y se transforma según las condiciones de la comunicación" (Aicher 1989: 18). 


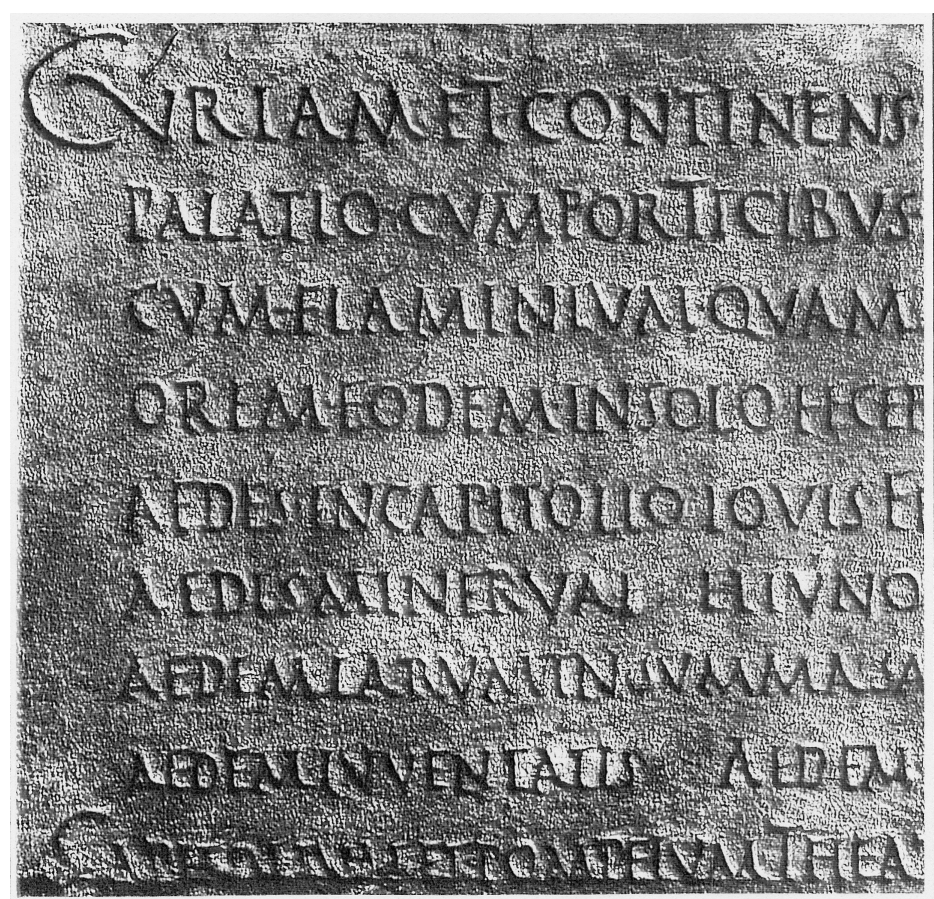

Figura 2

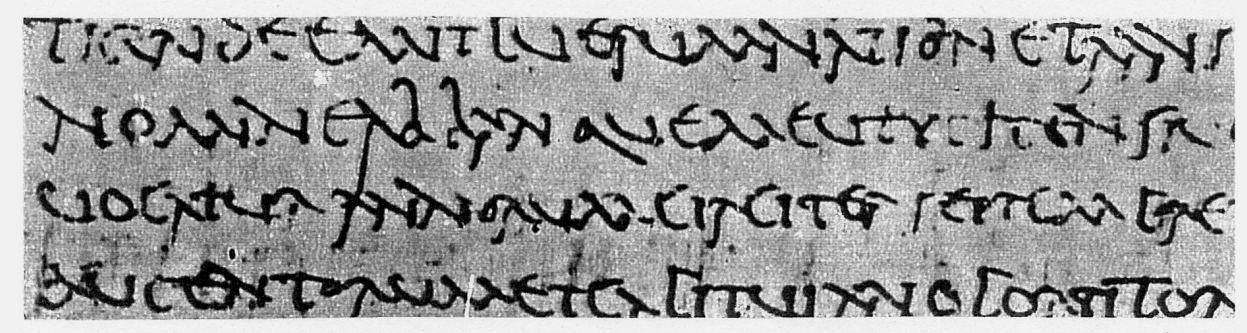

Figura 3

En forma más o menos paralela se desarrolla la letra uncial, sobre todo del siglo IV al IX, y básicamente entre los cristianos (Fig. 4). Su diseño tenía marcados acentos arqueados que permitían percibir el espíritu de la época de la arquitectura romana y, además, cierta influencia oriental (Földes 1987: 183). La expansión del cristianismo conlleva también la difusión de este tipo de escritura. De ella se deriva luego la letra media uncial (Fig. 5) que culmina aproximadamente en el siglo VIII con la aparición de las minúsculas.

Se evoluciona así hasta la carolingia minúscula medieval (Fig. 6 y 7), un maravilloso tipo de letra sobre cuyos orígenes y creador nada se conoce. Sólo sabemos que desplazó a todos los otros tipos de escritura locales, llegando a generalizarse su uso con mucha rapidez en toda Europa. Su exitosa difusión no fue casual, sino consecuencia de su buen diseño, pues su resumida imagen gráfica y la particularidad de sus trazos posibilitaba un proceso de lectu- 


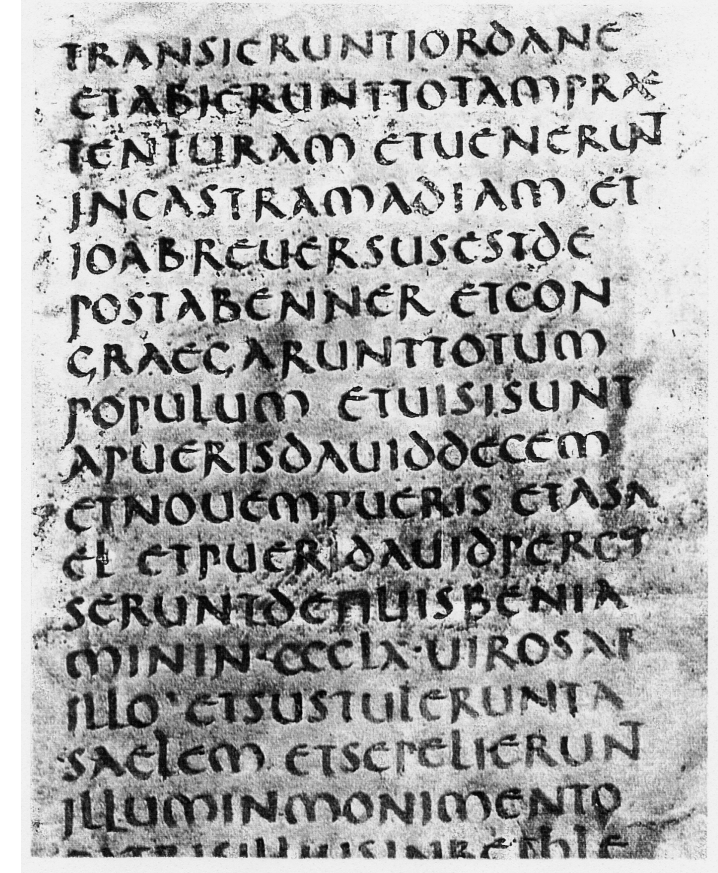

Figura 4

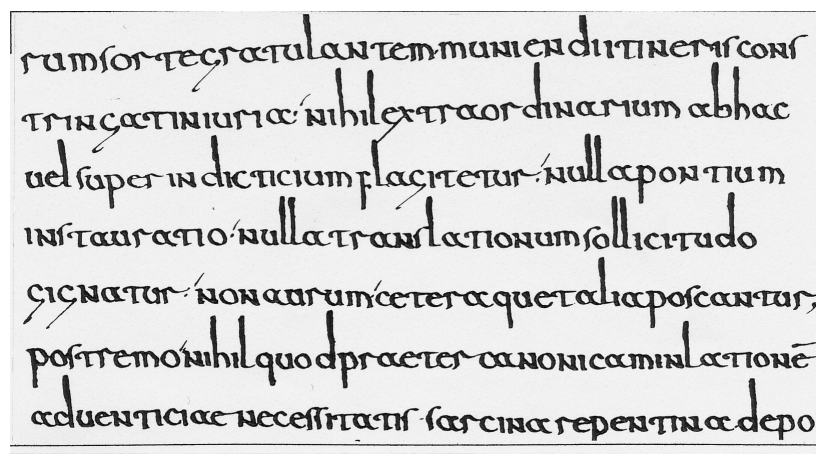

Figura 5

Dniroabre uerbum euangelizanabur. uir arcem multam.

Rexuirtaram. di leca dilecaret trone fur seepram - intrellectur primo duine pagane leuion dam eftrmaum - ovox traqu ut legrtur: inuent in tho decuplum

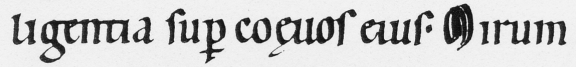
dum trnera etar cetefth rradha 
ra más rápido (Ruder 1988: 12). Su diseño combina elementos de la escritura cursiva romana con otros de la escritura céltica, tales como el uso de cuatro líneas guía para disponer los trazos ascendentes y descendentes de las letras. La escritura carolingia minúscula fue decretada por Carlomagno en el año 789, como la letra única de su imperio (Stankowski 1989: 80). Es también la precursora del alfabeto contemporáneo.

En el siglo XII cambia el espíritu de la época y surge un nuevo estilo: el gótico. Se hizo sentir primero en la arquitectura, pero su influencia se extendió a todos los campos de la creación, llegando hasta la escritura (Fig. 8). La escritura gótica alcanza el momento de la invención de la imprenta y se convierte así en la primera tipografía de tipo industrial.

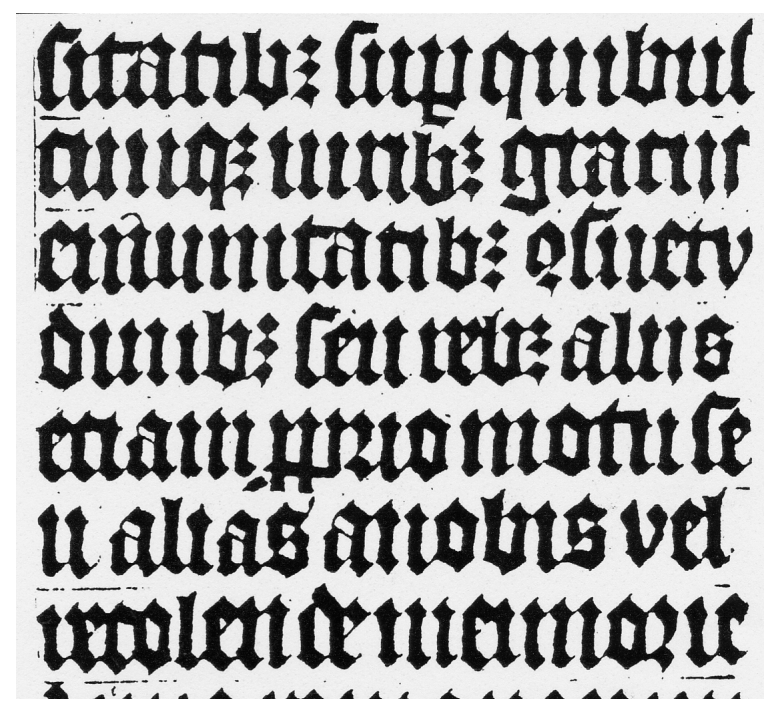

Figura 8

\section{La especialización del trabajo}

Los mil años que duró la Edad Media o "período del oscurantismo" — desde el siglo $\mathrm{V}$ hasta el siglo XV - significaron un enorme desarrollo en lo que hoy conocemos como Diseño Gráfico. La escritura como expresión gráfica evoluciona y se adapta cada vez mejor a los trazos manuales, en función no sólo de la comunicación sino también de la estética de sus proporciones y diseño. Su desarrollo implica el descubrimiento y empleo de nuevos materiales y herramientas, así como la especialización cada vez mayor de quienes la practicaban. En todos esos procesos hay que reconocer el papel determinante que desempeñó la fe cristiana y su afán por preservar y continuar con los escritos religiosos. Los monasterios se convirtieron en importantes centros de actividad cultural, educacional e intelectual en los que, con el fin de salvaguardar el conocimiento, se realizaban "manuscritos iluminados" adornados con oro y plata. El calificativo de "iluminados" deriva precisamente del brillo producido por las láminas de oro al captar y reflejar la luz. No obstante, se denomina "manuscritos iluminados" a todos aquellos libros escritos, decorados e ilustrados a mano durante la Edad Media. 
Con el tiempo, la realización de esos libros se fue desarrollando y especializando. Así, "el empleo del decorado gráfico e ilustrativo, con el fin de reforzar visualmente el significado de la palabra, se volvió muy importante y los manuscritos iluminados se realizaban con extraordinario cuidado y sensibilidad de diseño"(Meggs 1991: 65). Para el desempeño de esas labores, era necesario contar con personas pacientes, sensibles y con habilidades manuales innatas. Para la producción de estos libros, los monasterios contaban con un espacio especial llamado scriptorium. El titular de ese espacio, el scripttori, era un erudito que conocía el griego y el latín, y que se desempeñaba como editor y director de arte. El copisti era el escribano, es decir, el encargado de la transcripción de textos. También participaba el iluminador o ilustrador, que era el artista responsable de ejecutar los ornamentos y las imágenes que servían de complemento visual del texto. Así, la página de un manuscrito estaba no sólo en estrecha relación con el discurso hablado, sino también con el arte plástico y con la ilustración a color. "La producción de manuscritos durante los mil años que duró la época medieval, creó un vasto vocabulario de formas gráficas, composición de páginas, estilos de letras, así como de técnicas" (Meggs 1991: 65). Comienza así la especialización y diversificación de las distintas áreas que, siglos más tarde, conformarían la industria editorial y el Diseño gráfico.

\section{Del papiro hasta el libro}

Junto al desarrollo que va experimentando el diseño de la escritura, evolucionan también los sustratos como portadores de información. En sus inicios, además de la piedra en edificaciones al servicio de los centros del poder, existían otros materiales de uso más cotidiano. El papiro proveniente de Egipto era uno de ellos y llegó a utilizarse en los despachos papales todavía en el siglo XI. También se usaban madera, arcilla, piezas planas de metal y tablillas de cera sostenidas en marcos de madera.

El pergamino, cuyo nombre proviene de la antigua ciudad de Pérgamo, en el Asia Menor, se volvió común alrededor del año 190 a. C. como respuesta a la escasez de papiro. Se trataba de una superficie apta para la escritura, hecha a base de pieles de animales tales como terneros, borregos y cabras. Su fabricación requería de un delicado proceso, como lo describe Meggs (1991: 62).

Estas refinadas láminas de cuero se elaboran lavando primero la piel y quitando todo el pelo o la lana. Luego la piel se estiraba ajustadamente en un marco y se raspaba para remover todo rastro de pelo o carne. Después de ser blanqueada con yeso, se suavizaba con piedra pómez.

Las dimensiones de la superficie utilizable del pergamino, junto con su flexibilidad y resistencia, hicieron que se fuera imponiendo y desplazando así al papiro. Además, el papiro sólo se utilizaba en forma de rollo, lo que complicaba mucho la búsqueda de información. Era además demasiado frágil y sus rayas verticales por el dorso imposibilitaban su utilización por ambos lados.

Casi al iniciarse la era cristiana en Roma y en Grecia, el pergamino se comienza a trabajar en un nuevo formato llamado codex, en el cual "el pergamino se reunía en grupos de dos, cuatro, u ocho hojas. Éstas se doblaban, cosían y combinaban en códices con páginas, como un libro moderno" (Meggs 1991: 62). El codex es la piedra angular de la industria editorial que se desarrollaría posteriormente, y que llega hasta nuestros días. A pesar de que el pa- 
piro y el pergamino se utilizaron por igual durante los primeros 400 años d. C., las ventajas del formato codex llegaron a imponerse entre los cristianos, preocupados ante todo por la durabilidad y la permanencia que ofrecía el nuevo material a sus escrituras, y por lo práctico de su almacenaje y su utilización. Los codex, en lugar de desenrollarse, se hojeaban cómodamente ofreciendo de ese modo una forma rápida de localizar la información. El formato codex llega a convertirse durante las últimas décadas del Imperio Romano en un símbolo del cristianismo en contraposición con los rollos de papiro, de carácter más bien pagano.

El pergamino fue desplazado más tarde por el papel, introducido en Europa por los árabes en el siglo XI. Se trata del medio que prevalece hasta nuestros días, y cuyos orígenes se remontan a China, al período comprendido entre los dos siglos anteriores y los dos posteriores a Cristo. En el año 105 d.C., el funcionario de la corte imperial china Tsai Lun documentó la fabricación de un material que fue producido mediante la desecación de una suspensión de fibras vegetales sobre un tamiz. Con esto se alude, por primera vez en forma oficial, a la fabricación de papel. El conocimiento del arte de producir papel se extendió a lo largo de la ruta comercial hacia Corea y Japón, más tarde al mundo árabe, y de allí a Europa. Originalmente, los pliegos de papel se fabricaban a mano, de uno en uno. A partir de 1798, y gracias a un invento del francés Louis Roberts que se terminó de desarrollar al inicio de la era industrial, hoy se puede producir papel en rollos casi infinitos y en el mínimo de tiempo.

El papel resultó ser un excelente medio en momentos en los que el pergamino había dejado de ser adecuado a causa del incremento que había experimentado la producción de libros por el paulatino desarrollo de las universidades, sobre todo a partir del siglo XIII. Meggs (1991: 87) refiere este aspecto cuando describe cómo un solo libro de 200 páginas requería 25 pieles de carnero para el pergamino, las cuales resultaban aún más caras que el trabajo del copista. La producción de papel en Europa comenzó en España e Italia. La fábrica italiana de papel Fabriano, que data de 1276, es una de las más antiguas en Occidente.

En este desarrollo mancomunado de las expresiones visuales precursoras del Diseño Gráfico y de la Literatura, llegamos al siglo XV. Entre 1439 y 1444 ocurre en Maguncia, Alemania, el singular acontecimiento de la invención de la imprenta por Johannes Gutenberg. Para algunos, fue el invento más importante de la Humanidad después de la escritura. Como bien lo expresa Müller-Brockmann (1986: 33) la imprenta

ha influido en forma fundamental en el desarrollo de todos los siglos posteriores. Por medio de ella pudo el trabajo mental del intelecto estar a disposición de los hombres de todas las partes del mundo y ser trasmitido a las generaciones futuras. Desde ese entonces, millones de personas fueron rescatadas de la ignorancia, y la educación universal se convirtió en una posibilidad concreta.

A pesar de que el arte de imprimir con tipos móviles había sido inventado en China (por Pi Sheng, 1023 y 1063 d. C.), fue Gutenberg (1387(?)-1468) quien lo convirtió en una tecnología altamente funcional. La imprenta no sólo significó la rápida reproducción de impresos, sino también la posibilidad de tirajes elevados y, en consecuencia, la difusión universal.

Con la invención de la imprenta desaparece el trabajo de transcripción manual de textos; pero se da paso a nuevos oficios. Surgen así el ilustrador-grabador en lámina de cobre y el diseñador de tipos. Este último es quien crea y dibuja los caracteres de las determinadas familias de letras para su fundición en metal, con los que posteriormente se lleva a cabo el trabajo de impresión. Con la invención de la imprenta aparece la tipografía y, como bien lo expresa McLuhan (1972: 215), 
...la explosión tipográfica prolongó la mente y la voz del hombre para reconstruir a escala mundial el diálogo humano, tendiendo un puente entre las edades, ya que viéndola simplemente como una acumulación de información o un medio nuevo para la rápida entrega de conocimientos, la tipografía puso fin, síquica y socialmente, al parroquialismo y al tribalismo en el espacio y en el tiempo.

Al igual que cualquier otra ocupación, el trabajo del tipógrafo está influenciado por las corrientes dominantes de su momento y su contexto. Con los medios de su tiempo produce impresos a partir de las necesidades de su época. La actividad tipográfica tiene dos aspectos: por una parte está comprometida con sus intenciones prácticas y por otra parte, toca los ámbitos formales artísticos. Por eso se comprende que los primeros alfabetos diseñados procuraran imitar, en la medida de lo posible, la escritura manual del medioevo. No obstante, con la imprenta, la expresión y el toque personal de los manuscritos medievales llegarían a desaparecer por completo. Se impone la tipografía, una expresión gráfica que "le da a la palabra su forma visible, y la preserva para el futuro" (Ruder 1988: 32).

De esa nueva etapa creativa y productiva, Meggs propone a Peter Schoeffer como primer diseñador gráfico de la historia. Schoeffer fue un "hábil asistente y capataz de Gutenberg" (1991: 95), que se desempeñó como artista, como diseñador de páginas y tipos, y como iluminador experimentado. Fue también comerciante de manuscritos y copista de la Universidad de París en 1449. Se supone que su papel fue clave en el desarrollo del formato y diseño de la famosa Biblia de 42 líneas, de la que sólo 47 copias han sobrevivido (Meggs 1991: 97).

A partir del invento de la imprenta, la industria editorial y el libro — como objeto que entraba a formar parte de la vida pública— se desarrollaron aceleradamente. "El libro fue la primera máquina de enseñanza y también la primera mercancía producida en serie" (McLuhan 1972: 218). Después de haber sido sólo un conglomerado de hojas cosidas, el libro se va configurando paulatinamente con las partes que hoy le conocemos: entre otras, las cubiertas o tapas, el lomo, la portada; o bien, elementos informativos técnicos como la marca comercial del impresor y el colofón. Los diseños de tipos también evolucionaron apartándose del afán de reproducir la escritura manual y adaptándose a nuevas tendencias estéticas y a consideraciones perceptuales. Muchos se han convertido en clásicos y siguen vigentes en la actualidad. Por ejemplo, el tipo de letra Garamond (Fig. 9). El nombre de esta tipografía corresponde al apellido de su creador, el francés Claude Garamond (1480-1561), un destacado diseñador y fundidor de tipos, editor y tallista de sellos. El alfabeto Garamond es uno de los más antiguos diseñados para la imprenta (fue creado en 1544), y estuvo inspirado a su vez en los alfabetos de la antigüedad (Müller-Brockmann 1986: 36).

\section{abcdefghijklmnopqrsß wXyz$$
\text { ABCDEFGHIJKLM }
$$$$
\text { PQRSTUVWXYZ }
$$

Figura 9 


\section{El Diseño Gráfico contemporáneo}

Las bases del Diseño Gráfico podemos observarlas con claridad en las labores desempeñadas por Schoeffer y Garamond. Desde siempre, esa actividad creativa y productiva estuvo caracterizada por el desempeño de diversas labores a la vez: además de artista, se era diseñador de páginas y tipos, iluminador o ilustrador, grabador y editor, por mencionar sólo los aspectos más relevantes.

El concepto Diseño Gráfico que conocemos hoy como parte de nuestra cotidianidad fue usado por primera vez en 1922, por el norteamericano William Addison Dwiggins (18801956) para describir sus actividades profesionales (Meggs 1991: 242). Dwiggins fue un diseñador de libros sumamente culto, formado en la "Frank Holme School of Illustration" de Chicago, bajo la tutela del profesor, diseñador, tipógrafo y editor Frederik W. Goudy. William Addison Dwiggins se destacó también como diseñador de tipos, ilustrador, tipógrafo e impresor y diseñador publicitario. Además fue el creador del tipo de letra de letra Caledonia, uno de los más usados para libros en los Estados Unidos (Friedl 1998: 198-9). El mismo creador del concepto Diseño Gráfico era, ante todo, un diseñador e ilustrador de libros. Ya desde su gestación, el concepto estuvo ligado estrechamente con la escritura, con el libro, y en un sentido más amplio y contemporáneo, con la comunicación visual en general.

En la segunda mitad de este siglo, con las tecnologías digitales modernas y con los cambios que ha experimentado la vida humana, el campo de acción del Diseño Gráfico se ha diversificado cada vez más. Para Dalley (1981:107),

la explosión actual del diseño gráfico comenzó en Europa en los años sesenta, aunque había empezado antes en los Estados Unidos. Tuvo su origen en la prosperidad del consumo, que provocó un aumento masivo de la publicidad, del periodismo, y de la publicación de libros, y también la expansión de la televisión y la radio.

Lo que comenzó con la producción de libros se fue ampliando, con el paso de los años, a los diarios, las revistas y demás productos editoriales. La industria editorial sigue siendo uno de los campos de acción más importantes del Diseño Gráfico. No obstante, la publicidad, el diseño de imágenes corporativas, la comunicación gráfica de exteriores e interiores y los nuevos medios tecnológicos como internet, entre otros, han disparado las posibilidades creativas y productivas del diseño gráfico a un punto en el que, de tan amplio el panorama, se dificulta su visualización total.

En su dimensión material, como documento impreso, o bien como imagen luminosa en la pantalla de un ordenador, la literatura sería en la actualidad impensable sin el complemento del Diseño Gráfico. Basta con observar que cada letra, como carácter visible, ha sido concebida y realizada por un diseñador antes de convertirse en ese elemento tan natural de nuestra cotidianidad. Cualquier texto que se imprima a modo de libro o que se ofrezca por medios virtuales como internet, tendrá que pasar en algún momento por las manos de diseñadores gráficos que atenderán ya la concepción de su cubierta, ya las imágenes que lo acompañan (ilustraciones, gráficos, fotografías) o bien las características del diseño de sus páginas o "pantallas" (en caso de ser virtual) que en Costa Rica llamamos "diagramación” y que en el ámbito internacional se conoce como layout. Así, Diseño Gráfico y Literatura conforman una hermandad al servicio de la difusión y de la preservación de la cultura, a la vez que permanecen 
como documentos históricos que reflejan y contienen las particularidades y el sentir de las distintas épocas que atraviesan.

\section{Notas}

1. Las citas del alemán y del inglés fueron traducidas por el autor

\section{Bibliografía}

Aicher, Otl. 1989. Typographie. Berlin: Ernst \& Sohn Verlag.

Dalley, Terence. 1981. Guía Completa de Ilustración y Diseño. Madrid: H. Blume Ediciones.

Földes-Papp, K. 1987. Vom Felsbild zum Alphabet. Die Geschichte der Schrift. Stuttgart: Besler Verlag.

Friedl F., Ott N., Stein, B. 1998. Typographie. Wann, wer, wie. Köln: Könemann Verlag.

Haarmann, Harald. 1991. Universalgeschichte der Schrift. Frankfurt: Campus Verlag.

Korger, Hildegard. 1986. Schrift und Schreiben. Leipzig: VEB Fachbuchverlag.

McLuhan, Marshall. 1972. La comprensión de los medios como las extensiones del hombre. México: Editorial Diana.

Meggs, Philip B. 1991. Historia del Diseño Gráfico. México: Editorial Trillas.

Müller-Brockmann, J. 1986. A History of Visual Communication. Niederteufen: Verlag Arthur Niggli AG.

1982. Sistema de Retículas. Barcelona: Editorial Gustavo Gili, S.A.

Ruder, Emil. 1988. Typographie. Stuttgart: Verlag Gerd Hatje.

\section{Sitio Web}

McLuhan, Marshall. 1997. Medien verstehen. Der McLuhan-Reder. Internet: http: //194.173.66.100/index.html

- Was bedeutet Papier heute. Internet:

http://www.rz.fh-muenchen.de/home/fb/fb05/vf/d_papier.htm 
Was ist Literatur? Internet: http://www.geocities.com/CollegePark/Library/9546/literatur.htm

\section{Índice de láminas}

Fig. 1: Columna de Trajano. Korger, Hildegard: Schrift und Schreiben. VEB Fachbuchverlag. Leipzig 1986 (Págs. 74-5).

Fig. 2: $\quad$ Escritura rústica. Földes-Papp, K.: Vom Felsbild zum Alphabet. Die Geschichte der Schrift. Besler Verlag. Stuttgart 1987 (Pág. 181).

Fig. 3: Capital cursiva. Korger, Hildegard: Schrift und Schreiben. VEB Fachbuchverlag. Leipzig 1986 (Pág. 84).

Fig. 4: Letra Uncial. Földes-Papp, K.: Vom Felsbild zum Alphabet. Die Geschichte der Schrift. Besler Verlag. Stuttgart 1987 (Pág. 184).

Fig. 5: $\quad$ Letra Media Uncial. Földes-Papp, K.: Vom Felsbild zum Alphabet. Die Geschichte der Schrift. Besler Verlag. Stuttgart 1987 (Pág. 185).

Fig. 6 y 7: Letra carolingia minúscula medieval. Korger, Hildegard: Schrift und Schreiben. VEB Fachbuchverlag. Leipzig 1986 (Pág. 88).

Fig. 8: Letra gótica. Korger, Hildegard: Schrift und Schreiben. VEB Fachbuchverlag. Leipzig 1986 (Pág. 91).

Fig. 9: Letra Garamond. Müller-Brockmann, J.: Sistema de Retículas. Editorial Gustavo Gili, S.A. Barcelona 1982 (Pág. 21). 